\title{
AVALIAÇÃO DA CITOTOXICIDADE DO PEPTÍDEO ANTIMICROBIANO P34
}

\author{
FERNANDES, Maureen Hoch Vieira ${ }^{1}$; \\ SILVA, Débora Scopel $e^{2}$; \\ CASTRO, Clarissa Caetano de ${ }^{2}$; \\ CORRÊA, Rayra Almeida ${ }^{1}$; \\ VARGAS, Gilberto D'Ávila ${ }^{3}$; \\ FISCHER, Geferson ${ }^{3}$; \\ MOTTA, Amanda de Souza da ${ }^{4}$; \\ HÜBNER, Silvia de Oliveira ${ }^{3}$.
}

\footnotetext{
${ }^{1}$ Acadêmica da Faculdade de Veterinária da UFPEL, ${ }^{2}$ Doutoranda do Programa de Pós-Graduação em Veterinária da UFPEL, ${ }^{3}$ Médico Veterinário, Professor Doutor da Faculdade de Veterinária da UFPEL, ${ }^{4}$ Médica Veterinária, Professora Doutora do Instituto de Biociências da UFRGS.
}

\section{RESUMO}

$\mathrm{O}$ peptídeo antimicrobiano identificado como P34 foi obtido a partir de uma nova espécie de Bacillus isolada do conteúdo intestinal do peixe Piau-com-pinta (Leporinus sp.), presente na região da Bacia Amazônica. A atividade do P34 já foi demonstrada in vitro contra Listeria monocytogenes e herpesvírus bovino. Entretanto, para o desenvolvimento de novos agentes terapêuticos é essencial, inicialmente, uma avaliação dos seus níveis de toxicidade. O presente trabalho relata a avaliação da citotoxicidade do peptídeo P34 in vitro, usando o ensaio de vermelho neutro como método de determinação da viabilidade celular. Células CRFK (Crandell rees feline kidney), RK13 (Rabbit kidney), VERO (African green monkey kidney), MDCK (Madin-Darby canine kidney) e MDBK (Madin-Darby bovine kidney) foram cultivadas durante 24 horas e posteriormente expostas ao antimicrobiano P34, em diferentes concentrações, por 48 horas. A análise pelo ensaio de vermelho neutro demonstrou diferentes níveis de toxicidade, variando de acordo com a linhagem celular avaliada. As linhagens que permitiram uma concentração mais elevada do peptídeo P34 foram a RK13, MDBK e MDCK, com concentrações de 1,15 $\mu \mathrm{g} \cdot \mathrm{ml}^{-1}, 1,07 \mu \mathrm{g} \cdot \mathrm{ml}^{-1}$ e 1,0 $\mu \mathrm{g} \cdot \mathrm{ml}^{-1}$. Já as linhagens VERO e CRFK toleraram uma menor concentração do peptídeo para não apresentarem efeito citotóxico, sendo as concentrações de $0,75 \mu \mathrm{g} \cdot \mathrm{ml}^{-1}$ e 0,5 $\mu \mathrm{g} \cdot \mathrm{ml}^{-1}$, respectivamente.

Palavras-chave: Peptídeo antimicrobiano. Citotoxicidade. Linhagem celular. 


\section{INTRODUÇÃO}

Os peptídeos antimicrobianos representam uma nova classe de drogas terapêuticas com atividade antimicrobiana contra um grande número de agentes, incluindo muitos já resistentes às drogas tradicionais (HANCOCK et al., 2000). Eles têm sido isolados de uma grande variedade de animais, vertebrados e invertebrados, plantas, bem como de bactérias e fungos, sendo mobilizados logo após uma infecção microbiana e agindo rapidamente para neutralizar o agente invasor (REDDY et al., 2004). Segundo Hancock et al. (2006), os peptídeos antimicrobianos possuem, em sua maioria, ação rápida e potente, além de possuir um espectro, extraordinariamente, amplo de atividade, sendo consequentemente, considerados como novas promessas terapêuticas contra agentes infecciosos. No entanto, antes de serem feitos testes desses peptídeos em infecções clínicas, é indispensável fazer uma investigação inicial in vitro da toxicidade causada às células quando expostas a essas substâncias (MAHER et al., 2006).

Em pesquisas realizadas na Bacia Amazônica visando encontrar bactérias produtoras de atividade antimicrobiana, foi isolada uma nova espécie de Bacillus do conteúdo intestinal do peixe Piau-com-pinta (Leporinus sp.), sendo, posteriormente, caracterizada e identificada como Bacillus sp. linhagem P34 (MOTTA et al., 2004). Essa bactéria produz um peptídeo que foi denominado P34 e apresentou atividade antimicrobiana contra algumas bactérias patogênicas como Listeria monocytogenes, Bacillus cereus, Pasteurella haemolytica, Salmonella gallinarum, entre outras. A substância P34 foi purificada, seu peso molecular determinado por eletroscopia de massas como $1456 \mathrm{Da}$, e se apresentou relativamente estável ao calor e sensível às enzimas proteolíticas, sugerindo ser uma substância do tipobacteriocina (MOTTA et al., 2007). O seu modo de ação foi avaliado em trabalhos frente a bactérias, principalmente $L$. monocytogenes, sendo observado efeito bactericida, sugerindo ruptura de parede celular ocasionando a perda de constituintes intracelulares, analisada por microscopia eletrônica de transmissão (MOTTA et al., 2008). Estudos recentes indicam ação do peptídeo P34 como agente antiviral agindo sobre herpesvírus bovino tipo 1, sendo detectada redução do título viral (MEDEIROS et al., 2010) e exibindo atividade virucida sobre o vírus da arterite equina (SCOPEL et al., 2011). 
Há vários métodos de estudo da viabilidade celular em cultura de células, sendo realizados ensaios em microplacas, pois dessa forma é possível analisar rápido e simultaneamente um maior número de concentrações a serem testadas. Esses ensaios de citotoxicidade utilizam diferentes parâmetros visando identificar proliferação e morte celular, as quais podem ser avaliadas por colorimetria e absorbância devido à incorporação de certas substâncias (WEYERMANN et al., 2005).

O ensaio de vermelho neutro foi originalmente desenvolvido para avaliar a citotoxicidade in vitro de agentes químicos, usando cultura de células de mamíferos (BABICH et al., 1990). Esse ensaio é baseado na absorção e ligação do vermelho neutro, que é um corante catiônico, na matriz lisossomal de células viáveis depois de sua incubação juntamente com o agente que será avaliado quanto à toxicidade. Apenas os lisossomos de células saudáveis retêm permanentemente o corante catiônico depois de uma absorção inicial; nas células nas quais a integridade da membrana dos lisossomos foi comprometida pela exposição ao químico, o corante não é retido (SVENDSEN et al., 2004). Os mecanismos que causam a alteração na estabilidade da membrana dos lisossomos ainda não são totalmente conhecidos, mas podem envolver efeitos diretos das substâncias químicas na membrana da célula ou aumentar a frequência de lisossomos secundários em células submetidas à exposição com a substância tóxica (MAYER et al., 1992). Ensaios de citotoxicidade in vitro são necessários para definir a toxicidade do composto avaliado em determinado cultivo celular, indicando a habilidade intrínseca desse composto em causar morte celular como uma consequência de danos nas funções celulares (WEYERMANN et al., 2005).

O objetivo deste trabalho foi a avaliar a citotoxicidade do peptídeo antimicrobiano P34 em diferentes linhagens celulares usando o ensaio do vermelho neutro como método de análise da viabilidade celular.

\section{MATERIAL E MÉTODOS}

\section{Peptídeo antimicrobiano P34}

O peptídeo P34 foi extraído a partir de uma cultura de Bacillus sp. 34 (linhagem P34). A bactéria foi cultivada em frascos Erlenmeyer com $100 \mathrm{ml}$ de meio caldo TSB a $30^{\circ} \mathrm{C} \mathrm{em} \mathrm{pH}$ 7,0, em uma incubadora com agitação a 125 rpm por 24 horas. Após o cultivo, foi feita a 
purificação do P34 com sulfato de amônio a $20 \%$ de saturação e cromatografia de gelfiltração em uma coluna Sephadex G-100 (MOTTA et al., 2007). As frações ativas foram reunidas e a concentração analisada pelo método de Lowry et al. (1951). O peptídeo resultante foi diluído em meio essencial mínimo com sais de Eagle (E-MEM) para a utilização nos ensaios de toxicidade.

\section{Cultura de células}

Células CRFK (Crandell rees feline kidney), RK13 (Rabbit kidney), VERO (African green monkey kidney), MDCK (Madin-Darby canine kidney) e MDBK (Madin-Darby bovine kidney) foram preparadas em microplacas de 96 poços com E-MEM suplementado com $10 \%$ de soro fetal bovino (Gibco), enrofloxacina $\left(10 \mathrm{mg} \cdot \mathrm{ml}^{-1}\right)$ e anfotericina $B\left(0,025 \mu \mathrm{g} \cdot \mathrm{ml}^{-1}\right)$. As células foram mantidas a $37{ }^{\circ} \mathrm{C}$ em uma estufa com $5 \%$ de $\mathrm{CO}_{2}$ e, após confluência, $100 \mu$ das diluições seriadas $\left(3\right.$ a $0,325 \mu \mathrm{g} \cdot \mathrm{ml}^{-1}$ ) do peptídeo P34 foram adicionadas ao cultivo celular. As placas foram incubadas com o P34 por 48 horas adicionais nas mesmas condições. Células não tratadas foram mantidas como controle.

\section{Ensaio do Vermelho Neutro}

Após 48 horas de incubação com as diferentes concentrações do peptídeo, foi retirado o meio contendo P34 e adicionado $200 \mu \mathrm{l}$ de uma solução de vermelho neutro a $0,033 \%$ em cada poço da microplaca. Após incubação de 2 horas a $37{ }^{\circ} \mathrm{C}$ em estufa com $5 \%$ de $\mathrm{CO}_{2}$, a solução foi removida e as células lavadas com E-MEM. A incorporação do corante pelas células foi analisada após solubilização, pela adição de $100 \mu \mathrm{L}$ de uma solução contendo etanol $50 \%$, ácido acético $1 \%$ e água destilada q.s.p. A placa foi mantida a temperatura ambiente por $10 \mathrm{~min}$, e foi realizada a leitura das densidades ópticas em um espectrofotômetro em comprimento de onda de $540 \mathrm{~nm}$.

\section{Cálculo da viabilidade celular}

A percentagem de viabilidade foi calculada mediante a fórmula AT/AC X 100, sendo AT e AC a absorbância dos tratados e a absorbância dos controles, respectivamente. Foram consideradas concentrações não tóxicas as que permitiram uma viabilidade celular maior que $90 \%$ quando comparada com o controle de células. 


\section{RESULTADOS E DISCUSSÃO}

O ensaio de vermelho neutro permitiu detectar concentrações tóxicas do peptídeo P34 variando conforme o tipo celular. As linhagens celulares que permitiram uma concentração mais elevada do peptídeo P34 foram a RK13, MDBK e MDCK, com concentrações em torno

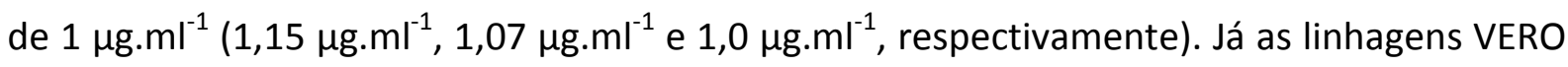
e CRFK toleraram uma menor concentração do peptídeo para não apresentarem efeito citotóxico, sendo as concentrações de $0,75 \mu \mathrm{g} \cdot \mathrm{ml}^{-1}$ e $0,5 \mu \mathrm{g} \cdot \mathrm{ml}^{-1}$, respectivamente. Nas concentrações acima descritas, a viabilidade celular foi calculada em comparação com células não tratadas. Dessa forma, foi observado um percentual de $93 \%$ de viabilidade na cultura de CRFK, 92\% na cultura de MDBK, 97\% na cultura de MDCK, 99,6\% na cultura de RK13 e 100\% de viabilidade nas células VERO. Outros pesquisadores já relataram variações na sensibilidade de culturas de células para um dado agente antimicrobiano, incluindo diferentes processos de metabolismo e toxicidade. O mesmo agente pode se comportar de forma muito diferente dependendo do tipo de cultivo celular utilizado ( $\mathrm{HU}$ et al., 1989). O mecanismo exato que difere na toxicidade nos diferentes tipos celulares ainda não está totalmente elucidado, mas pode estar relacionado com a hidrofobicidade da superfície celular (VAUCHER et al., 2009), ou mesmo por diferenças na absorção do agente nos tipos celulares (FOTAKIS et al., 2006). Além disso, já foi relatado que fatores intrínsecos das células influenciam na sua sensibilidade a substâncias tóxicas, incluindo biotransformação química e formas de ligação, características de permeabilidade da membrana e determinantes de superfície, vias de síntese intracelular e mecanismos de adaptação e de recuperação (EKWALL et al., 1990).

\section{CONCLUSÃO}

Estudos com peptídeos antimicrobianos podem permitir o desenvolvimento de novas drogas contra doenças infecciosas, com potencial para uma abordagem totalmente nova no tratamento de infecções causadas por microrganismos. Algumas características dos peptídeos os tornam atraentes agentes terapêuticos, tais como a capacidade de agir como imunomoduladores nas respostas imunes, suas ações antissépticas e antimicrobianas, propriedades adjuvantes, além da baixa toxicidade celular geralmente detectada (BROWN et 
al., 2006; HANCOCK et al., 2006). Os resultados obtidos no presente estudo confirmam a baixa citotoxicidade do peptídeo antimicrobiano P34, sugerindo um alto potencial como um futuro agente antimicrobiano. Avaliações adicionais para a determinação de outros microorganismos suscetíveis ao peptídeo bem como investigações mais detalhadas sobre o seu mecanismo de ação devem ser realizadas.

\section{EVALUATION OF CYTOTOXICITY OF P34 ANTIMICROBIAL PEPTIDE}

\section{ABSTRACT}

A new antimicrobial peptide identified as P34 was obtained from a new Bacillus species isolated from the intestinal contents of the fish Piau-com-pinta (Leporinus sp.) in the region of the Amazon basin. The P34 peptide demonstrated activity against Listeria monocytogenes and bovine herpesvirus in vitro. However, it is essential for the development of new therapeutic agents an evaluation of its levels of toxicity in vitro. This paper describes the assessment of cytotoxicity of P34 peptide in vitro using the neutral red assay as a method for determination of cell viability. CRFK (Crandell rees feline kidney), RK13 (Rabbit kidney), VERO (African green monkey kidney), MDCK (Madin-Darby canine kidney) and MDBK (Madin-Darby bovine kidney) cells were cultured for 24 hours and exposed to the antimicrobial P34 in different concentrations for 48 hours. The analysis by neutral red assay showed different levels of toxicity depending on the cell lineage. The cell lines which tolerate a higher concentration of P34 peptide were RK13, MDBK and MDCK, with concentrations of $1.15 \mu \mathrm{g} \cdot \mathrm{ml}^{-1}, 1.07 \mu \mathrm{g} \cdot \mathrm{ml}^{-1}$ and $1.0 \mu \mathrm{g} \cdot \mathrm{ml}^{-1}$. On the other hand, concentrations of $0.75 \mu \mathrm{g} \cdot \mathrm{ml}^{-1}$ and $0.5 \mu \mathrm{g} \cdot \mathrm{ml}^{-1}$ had no cytotoxic effect in the CRFK and VERO, respectively.

Keywords: Antimicrobial peptide. Cytotoxicity. Cell line. 


\section{EVALUACIÓN DE LA CITOTOXICIDAD DEL PÉPTIDO ANTIMICROBIANO P34}

\section{RESUMEN}

U

n nuevo péptido antimicrobiano identificado como P34 se obtuvo de una nueva especie de Bacillus aislado del contenido intestinal del pez Piau-com-pinta (Leporinus sp.), presente en la región de la cuenca del Amazonas. El péptido P34 mostró actividad in vitro contra Listeria monocytogenes y el herpesvirus bovino. Para el desarrollo de nuevos agentes terapéuticos es esencial la evaluación de sus niveles de toxicidad. Este trabajo describe la evaluación de la citotoxicidad del péptido P34 in vitro utilizando el ensayo de captación del rojo neutro como un método para determinar la viabilidad celular. Las células CRFK (Crandell rees feline kidney), RK13 (Rabbit kidney), VERO (African green monkey kidney), MDCK (Madin-Darby canine kidney) y MDBK (Madin-Darby bovine kidney) se cultivaron durante 24 horas y se expusieron a la P34 antimicrobiano en diferentes concentraciones, durante 48 horas. El análisis por ensayo de rojo neutro mostró distintos niveles de toxicidad, evaluado según la célula. Las líneas celulares que permitieron una mayor concentración de péptido P34 eran RK13, MDBK y MDCK, con concentraciones de $1,15 \mu \mathrm{g} \cdot \mathrm{ml}^{-1}, 1,07 \mu \mathrm{g} \cdot \mathrm{ml}^{-1}$ y $1,0 \mu \mathrm{g} \cdot \mathrm{ml}^{-1}$. Las cepas CRFK y VERO permitieron una menor concentración del péptido, no hubo efecto citotóxico a concentraciones de $0,75 \mu \mathrm{g} \cdot \mathrm{ml}^{-1}$ y 0,5 $\mu \mathrm{g} \cdot \mathrm{ml}^{-1}$, respectivamente.

Palabras clave: Péptido antimicrobiano. Citotoxicidad. Línea celular.

\section{REFERÊNCIAS}

BABICH, H.; BORENFREUND, E. Applications of the neutral red cytotoxicity assay to in vitro toxicology. Alternatives to laboratory animals, v. 18, p. 129-144, 1990.

BROWN, K. L.; HANCOCK, R. E. Cationic host defense (antimicrobial) peptides. Current Opinion in Immunology, v. 18, p. 24-30, 2006.

EKWALL, B.; SILANO, V.; PAGANUZZI-STAMMATI, A.; et al. Toxicity tests with mammalian cell cultures. In: BOURDEAU, E.; SOMERS, E.; RICHARDSON, G. M.; et al. Short-term Toxicity Tests for Non-Genotoxic Effects. Chicester: John Wiley \& Sons Ltda, 1990. Cap. 7, p. 75-97.

FOTAKIS, G.; TIMBRELL, J. A. In vitro cytotoxicity assays: Comparison of LDH, neutral red, MTT and protein assay in hepatoma cell lines following exposure to cadmium chloride. Toxicology Letters, v. 160, p. 171-177, 2006.

HANCOCK, R. E.; SCOTT, M. G. The role of antimicrobial peptides in animal defenses. Proceedings of the National Academy of Sciences, USA, v. 97, p. 8856-8861, 2000. 
HANCOCK, R. E.; SAHL, H. G. Antimicrobial and host-defense peptides as new antiinfective therapeutic strategies. Nature Biotechnology, v. 24, p. 1551-1557, 2006.

HU, J. M.; HSIUNG, G. D. Evaluation of new antiviral agents: I. In vitro perspectives. Antiviral Research, v. 11, p. 217-232, 1989.

LOWRY, O. H.; ROSEBROUGH, N. J.; FARR, A. L.; et al. Protein measurement with Folin phenol reagent. Journal of Biological Chemistry, v. 193, p. 265-275, 1951.

MAHER, S.; MCCLEAN, S. Investigation of the cytotoxicity of eukaryotic and prokaryotic antimicrobial peptides in intestinal epithelial cells in vitro. Biochemical Pharmacology, v. 71, n. 9, p. 1289-1298, 2006.

MAYER, F. L.; VERSTEEG, D. J.; MCKEE, M. J.; et al. Physiological and nonspecific biomarkers. In: HUGGETT, R. J.; et al. Biomarkers: Biochemical, Physiological, and Histological Markers of Anthropogenic Stress. Boca Raton: Lewis Publishers, 1992, p. 125-153.

MEDEIROS, D. M.; SANT ANNA, V.; BRANDELLI, A.; et al. Determination of suppressive activity of the antimicrobial peptide P34 isolated from a Bacillus strain of the aquatic amazon region on herpesvirus. In: XXI ENCONTRO NACIONAL DE VIROLOGIA / V ENCONTRO DE VIROLOGIA DO MERCOSUL, 2010, Gramado. Resumos. Gramado: SBV, 2010.

MOTTA, A. S.; CLADERA-OLIVERA, F.; BRANDELLI, A. Screening for antimicrobial activity among bactéria isolated from the Amazon basin. Brazilian Journal of Microbiology, v. 35, $n$. 4, p. 307-310, 2004.

MOTTA, A. S.; LORENZINI, D.; BRANDELLI, A. Purification and partial characterization of an antibacterial peptide produced by a novel Bacillus sp. strain isolated from Amazon basin. Current Microbiology, v. 54, p. 282-286, 2007.

MOTTA, A. S.; FLORES, F. S.; SOUTO, A. A.; et al. Antibacterial activity of a bacteriocin-like substance produced by Bacillus sp. P34 that targets the bacterial cell envelope. Antonie van Leeuwenhoek, v. 93, p. 275-284, 2008.

REDDY, K. V. R.; YEDERY, R. D.; ARANHA, C. Antimicrobial peptides: premises and promises. International Journal of Antimicrobial Agents, v. 24, n. 6, p. 536-547, 2004.

SCOPEL, D.; CASTRO, C. C.; HÜBNER, S. O.; et al. Avaliação da atividade virucida de um peptídeo antimicrobiano (P34) produzido por uma linhagem de Bacillus sp. sobre o vírus da arterite equina. In: XIII ENPOS UFPEL, 2011, Pelotas. Anais. Pelotas: ENPOS UFPEL, 2011.

SVENDSEN, C.; SPURGEON, D. J.; HANKARD, P. K.; et al. A review of lysosomal membrane stability measured by neutral red retention: Is it a workable earthworm biomarker.

Ecotoxicology and Environmental Safety, v. 57, p. 20-29, 2004. 
VAUCHER, R. A.; TEIXEIRA, M. L.; BRANDELLI, A. Investigation of the cytotoxicity of antimicrobial peptide P40 on eukaryotic cells. Current microbiology (print), v. 60, n. 1, p. 1-5, 2010.

WEYERMANN, J.; LOCHMANN, D.; ZIMMER, A. A practical note on the use of cytotoxicity assays. International Journal of Pharmaceutics, Amsterdam, v. 288, p. 369-376, 2005.

Autor para correspondência: Maureen Hoch Vieira Fernandes - Acadêmica da Faculdade de Veterinária da UFPEL. Laboratório de Virologia e Imunologia, Campus Capão do Leão, Pelotas (RS). CEP 96010-900, CP 354. maureenhvfernandes@yahoo.com.br 